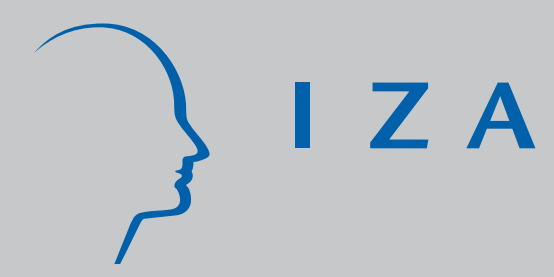

IZA DP No. 3877

Education and Early Career Outcomes of Second-Generation Immigrants in France

Christian Belzil

François Poinas

December 2008 


\title{
Education and Early Career Outcomes of Second-Generation Immigrants in France
}

\author{
Christian Belzil \\ Ecole Polytechnique, ENSAE, \\ CIRANO and IZA \\ François Poinas \\ GATE, University of Lyon
}

\section{Discussion Paper No. 3877 \\ December 2008}

\author{
IZA \\ P.O. Box 7240 \\ 53072 Bonn \\ Germany \\ Phone: +49-228-3894-0 \\ Fax: +49-228-3894-180 \\ E-mail: iza@iza.org
}

\begin{abstract}
Any opinions expressed here are those of the author(s) and not those of IZA. Research published in this series may include views on policy, but the institute itself takes no institutional policy positions.

The Institute for the Study of Labor (IZA) in Bonn is a local and virtual international research center and a place of communication between science, politics and business. IZA is an independent nonprofit organization supported by Deutsche Post World Net. The center is associated with the University of Bonn and offers a stimulating research environment through its international network, workshops and conferences, data service, project support, research visits and doctoral program. IZA engages in (i) original and internationally competitive research in all fields of labor economics, (ii) development of policy concepts, and (iii) dissemination of research results and concepts to the interested public.
\end{abstract}

IZA Discussion Papers often represent preliminary work and are circulated to encourage discussion. Citation of such a paper should account for its provisional character. A revised version may be available directly from the author. 
IZA Discussion Paper No. 3877

December 2008

\section{ABSTRACT}

\section{Education and Early Career Outcomes of Second-Generation Immigrants in France*}

We estimate a flexible dynamic model of education choices and early career employment outcomes of the French population. Individuals are allowed to choose between 4 options: continue to the next grade, accept a permanent contract, accept a temporary contract, or withdraw from the labor force (a residual state). Our analysis focuses on the comparison between French Second-Generation Immigrants whose parents are born in Africa and French-natives. We find that schooling attainments explain around two thirds of the differences in access to early career employment stability. However, one third cannot be linked to observed investment in human capital.

JEL Classification: $\quad$ I2, J15, J24, J41

Keywords: second-generation immigrants, schooling attainments, fixed term employment

Corresponding author:

Christian Belzil

Ecole Polytechnique

Département d'Economie

91128 Palaiseau Cedex

France

E-mail: christian.belzil@polytechnique.edu 


\section{Introduction}

Continental European labor markets are often pictured as being characterized by a relatively low degree of flexibility, when compared to Anglo-Saxon countries. This is particularly the case for France and Italy (OECD, 1999, Table 2.2). This inflexibility is particularly acute at the firing level. In practice, it implies that individuals holding employment must be paid relatively high severance pay in case employment downsizing is necessary. ${ }^{1}$ As a consequence, firms may be reluctant to grant permanent contracts to new hires and favor limited term contracts. ${ }^{2}$ This theoretical prediction is largely supported by the data. About 30\% of newly hired workers in the French labor market get a permanent contract for their first job, although the share of permanent contracts in total employment is $86 \%$ (INSEE, Enquête emploi, 2005).

At the same time, the high incidence of criminal activities and social turmoil in areas densely populated with immigrants has pushed French policy makers to question the level of integration of second generation immigrants. In 1999, the unemployment rate of second generation immigrants aged 19-29 was $30 \%$ (nearly $40 \%$ if the parents came from Algeria or Morocco), whereas it was $20 \%$ for children with both parents born in France. This inequality is also noticeable at the level of early career employment contracts. For instance, only $23 \%$ of second generation immigrants with both parents born in an African country get a permanent contract for their first job compared to $32 \%$ for young workers with both parents born in France. While discrimination has been advanced as a possible cause, potential differences in pre-market skill investment (such as differences in education) may also be important. From an economist perspective, differences in early career outcomes, between natives and second generation immigrants, which persist after conditioning on education, are particularly interesting. It is those differences that are important to quantify.

The poor performance of second generation immigrants has also attracted attention in European countries, like Denmark (Nielsen et al., 2003) and the Netherlands (Van Ours and Veenman, 2003). In the United States, the

\footnotetext{
${ }^{1} \mathrm{~A}$ vast literature deals with the impact of employment protection legislation (in particular firing costs) on unemployment and labor mobility (eg., Bentolila and Bertola, 1990; Bertola, 1990; Garibaldi, 1998; Mortensen and Pissarides 1999).

${ }^{2}$ Indeed, there is a considerable amount of debate going on between European countries about the optimal level of job and social security that the European economy can stand.
} 
economic performances of second generation immigrants appear to have been much better. For instance, Chiswick and DebBurman (2004) and Card (2005) find no gap in schooling attainments and wages between second generation immigrants and US-natives.

Surprisingly, and despite the recent incidence of violent crimes in French suburban regions, very few economists have investigated the relative performance of second generation immigrants in France. As of now, Aeberhardt and Pouget (2007) and Aeberhardt et al. (2007) are the only recent papers studying the wage gap between second generation immigrants and children of parents born in France. Both papers are based on econometric models in which schooling is assumed to be exogenous.

In this paper, we perform an econometric analysis of individual educational choices and early labor market outcomes. We estimate a reduced-form dynamic model of education and early career outcomes. We focus on the nature of the early career employment contracts and more precisely whether the term of the contract is fixed (limited) or permanent (unlimited). We model individual trajectories as a collection of sequential dynamic discrete choices, in the spirit of Cameron and Heckman (1998, 2001). We consider two sub-populations that are indexed by the country of origin of the parents: "French-natives" (those for whom both parents were born in France with French citizenship), and "African-natives" (those for whom both parents were born in an African country with a non-French citizenship).

At the outset, it should be pointed out that the model is very flexible. It assumes that, for each grade level completed, individuals are allowed to choose within a set that contains 4 options: i) continue to the next grade, ii) accept a Permanent Contract (PC), iii) accept a Fixed Term Contract (FTC), or iv) withdraw from the labor force (a residual state). So, given a completed grade level, each choice (each element in the set) has its own latent utility equation, which is parameterized as a function of a large set of parental background variables and unobserved heterogeneity. As in a standard Roy model, there exists a different set of equations for each possible grade level. This model allows us to measure separate effects of education level on the employment outcome probabilities. For instance, the effect of completed education on the likelihood of a particular early career outcome (say obtaining a permanent contract) is not captured by a single parameter but by a collection of several parameters characterizing individual unobserved abilities, and other parameters measuring the effect of parents' occupation, location and geographical origin on a given outcome. As a consequence, the 
model contains a very large number of parameters. ${ }^{3}$

Our general objective is to explain the schooling and employment outcomes of second generation immigrants from Africa and French-natives. We ask the following questions. Do parents' background and unobserved skills and motivation explain schooling attainments in the same way for Frenchnatives and African-natives? Is the schooling gap between French-natives and second generation immigrants sufficient to explain the early career employment gap? If not, what is the impact of education relative to other factors?

We now summarize the main findings. First, the relative impacts of observed and unobserved factors on the probability of reaching a particular grade level appear to be similar across groups. Around $60 \%$ of the crosssectional variance of the probability of completing five years of college is explained by parents' background, $15 \%$ by early cognitive skills and $25 \%$ by unobserved skills and motivation. For lower schooling attainments, like completing secondary school and more, the impact of parents' background is lower for both sub-samples (around 30\%), whereas early cognitive skills have a stronger impact for African-native attainments (59\% vs. 37 for Frenchnatives), and unobserved skills a smaller impact (15 vs. $34 \%$ ).

Second, the schooling gap between French and African-natives is not sufficient to explain the early career employment gap. $68 \%$ of the cross-sectional variance in the probability of obtaining a Permanent Contract as a first contract in the labor market is explained by schooling attainments. However, $32 \%$ of the differences across groups are associated to returns to observed or unobserved factors. This is much harder to explain. While this "employment quality gap" may be associated to differences in skills that prevail after conditioning on schooling, it may also be attributed to factors such as discrimination and the like.

Third, the share of the cross-sectional variance in the probability of obtaining a Permanent Contract decreases with experience. After two years in the labor market, it represents $62 \%$, which implies that returns to other observable and unobservable factors, such as experience, are higher (38\%).

\footnotetext{
${ }^{3}$ At a more philosophical level, the model may be labeled as semi-structural, since it is not based on a formal utility maximization procedure. It is also important to note that because the model is explicitly dynamic (education choices may affect post-schooling choices even after conditioning on unobserved heterogeneity), it cannot be logically estimated by IV techniques (the most popular method of estimation among empirical labor economists). For more details, see Keane (2007) and Belzil and Hansen (2008).
} 
In the following section, we introduce the database used in this article. The econometric model is described in the next part. Then, we present the results of estimations and conclude.

\section{The Data: Génération 98}

Our work is based on Génération 98, a large scale survey conducted in France by Céreq. ${ }^{4}$ It provides detailed information on the socio-demographic background and employment characteristics of young individuals who left school in the year 1998 and were interrogated in early 2001. Re-interviews have been conducted for half of the sample in 2003, but we do not use them here since we focus on employment conditions during the first two years after school completion. The aim of Génération 98 is to document many aspects of early labor market transitions. In particular, Génération 98 provides information on spells of employment, unemployment, and training experienced between school completion (labor market entrance) and the date of the survey. Therefore, information on three years of the generation's working life is available and each period of employment is well documented. The personal labor market history of survey respondents has been reconstructed, month by month, during the period 1998-2001.

Because Génération 98 is a national survey of those who left the educational system at a particular point in time (1998), all individuals faced the same labor market conditions after 1998.

\subsection{Parents' Country of Origin}

Our sample is composed of 42,674 individuals. The group of French-natives contains 40,525 individuals whose both parents were born in France and had the French citizenship at birth. The second group is composed of 2,149 African-natives, i.e. whose both parents were born in an African country and did not have the French citizenship at birth. Individuals belonging to this last group are also called second generation immigrants from Africa.

\footnotetext{
${ }^{4}$ French Center for Research on Education, Training and Employment.
} 


\subsection{Education}

In order to model education, we use the highest educational level (reached in 1998). The educational level variable falls in 7 categories: 1) no qualification; 2) vocational high school degree; 3) high school degree (baccalauréat, A level); 4) some college but leaving higher education without graduating; 5) technical or vocational college or ordinary college (baccalauréat and 2 years); 6) those graduated who completed 3 or 4 years of college and 7) those who completed 5 years of college and more, elite business or engineering school university degrees.

\subsection{Employment Contracts}

The data contain information on the nature of the employment contract at the beginning of each employment spell, as well as changes in the contract type within the spells. We create two categories of contracts, distinguished by their term, defined when the contract is signed by the employer and the employee.

The Permanent Contracts (PC) category regroups the CDI (contracts with indefinite duration) as well as contracts held by civil servants. The duration of a CDI is not set ex-ante and the employer has to pay a firing cost if he wants to lay-off a worker employed under such a contract.

The category named Fixed Term Contracts (FTC) refers to all types of contracts whose term is defined ex-ante. It regroups the CDD (contracts with limited duration), which is the most common form of fixed term employment, but also subsidized contracts, apprenticeship contracts and self-employment. Contrary to a CDI, no cost is supported by the employer at the end of a CDD, but CDD have to be used under some restrictions. According to the French legislation, a CDD cannot be used to fill a job that would exist under normal and permanent business conditions for a given firm. Moreover, a CDD can be renewed only once, and the maximum employment duration under a CDD can not exceed 18 months. 


\section{The Econometric Model}

We model schooling decisions as a sequential dynamic discrete choice model. ${ }^{5}$ At each grade level, individuals are assumed to make a choice between obtaining more schooling and labor market work. We model three different post-schooling outcomes: i) employed in a Permanent Contract (PC), ii) employed in a Fixed Term Contract (FTC) and iii) out of the labor force (Out), a residual state. ${ }^{6}$

Because the model is interpreted as the reduced-form of a more involved structure, the terms choices and outcomes may be used interchangeably. ${ }^{7}$

To estimate the model, we use several observable factors: family characteristics (parents' occupation and location), gender, immigration status and a cognitive skill indicator: "late at school". This variable indicates if the individual enters secondary school after being 11 years old, which is the "normal" age at which children attain this level without schooling delay. On top of these observable variables, we have to introduce an individual unobserved time invariant heterogeneity term, in order to control for educational selectivity. Indeed, there are unobservable factors, such as "motivation" or "ability", that influence schooling decisions at each grade level. Cameron and Heckman (1998) explain that ignoring these effects creates an omitted variable bias that understates the true effects of family background variables on educational attainments, especially at higher grades. Indeed, ability and family characteristics are negatively correlated at higher grades: individuals with low family background characteristics continue schooling only if they have a high ability.

As in Cameron and Heckman $(1998,2001)$, the model is specified as a sequence of multinomial logistic probabilities with unobserved heterogeneity. Let $C$ be the set of choices at the end of each grade level:

$$
C=\left\{s, c_{1}, c_{2}, c_{3}\right\}
$$

$c_{1}, c_{2}$ and $c_{3}$ are the 3 employment outcomes (respectively employed in a permanent job, employed in a fixed term job and out of the labor force),

\footnotetext{
${ }^{5}$ Modeling schooling decisions as a reduced-form transition (hazard) model has been done in Cameron and Heckman (1998, 2001), Belzil (2007).

${ }^{6}$ We do not distinguish here between unemployed workers who choose not to work, and unemployed workers who are searching for a job.

${ }^{7}$ For instance, the data does not allow us to distinguish individuals who accept limited term contracts because they received no permanent contract offer from those who actually accept a limited term contract over a permanent one.
} 
whereas $s$ corresponds to continuing schooling to the next grade level. ${ }^{8}$ At the end of grade $g, g=1, \ldots, 7$, where 1 is the lowest grade, the optimal choice for an individual $i$ is the following:

$$
\widehat{c}_{i, g}=\arg \max _{c \in C}\left\{U_{i, g, c}^{*}\right\}
$$

where $U_{i, g, c}^{*}$ is the utility from choosing option $c$, given completion of grade $g$. The expression of this latent variable is given by:

$$
U_{i, g, c}^{*}=X_{i} \beta_{g, c}+\nu_{i, g, c}
$$

where $X_{i}$ is a vector of observed variables, $\beta_{g, c}$ is a vector of parameters measuring the effects of these variables, and $\nu_{i, g, c}$ is unobservable by the econometrician.

The structure adopted for $\nu_{i, g, c}$ is

$$
\nu_{i, g, c}=\alpha_{g, c} \theta_{i}+\epsilon_{i, g, c}
$$

where $\theta_{i}$ is the individual specific effect, constant across grades and contractual outcomes, and which is orthogonal to the i.i.d. error term, denoted $\epsilon_{i, g, c}$. This particular form implies an individual specific intercept term, $\gamma_{i, g, c}=\alpha_{g, c} \theta_{i}$.

Then, assuming that $\epsilon_{i, g, c}$ is an iid extreme value variable, we can write the probability that an individual $i$ exits to the outcome $c$ once he achieved grade $g$ as an extension of McFadden's (1974) conditional logit model:

$$
\operatorname{Pr}\left(D_{i, g, c}=1 \mid X_{i}, \theta_{i}\right)= \begin{cases}\frac{\exp \left(X_{i} \beta_{g, c}+\gamma_{i, g, c}\right)}{1+\sum_{a=c_{1}}^{c_{3}} \exp \left(X_{i} \beta_{g, a}+\gamma_{i, g, a}\right)} & \text { for } c=c_{1}, \ldots, c_{3} \\ \frac{1}{1+\sum_{a=c_{1}}^{c_{3}} \exp \left(X_{i} \beta_{g, a}+\gamma_{i, g, a}\right)} & \text { for } c=s\end{cases}
$$

where $D_{i, g, c}=1$ if individual $i$ 's outcome after grade $g$ is $c \in C$, i.e. if $\widehat{c}_{i, g}=c$.

The probability that individual $i$ exits to the optimal outcome $\hat{c}$, after having completed the optimal grade level $\hat{g}$ defines the contribution to the likelihood for an individual $i$. Precisely, the individual likelihood is

$$
L_{i}\left(X_{i}, \theta_{i}\right)=\prod_{b=1}^{\hat{g}-1} \operatorname{Pr}\left(D_{i, b, s}=1 \mid X_{i}, \theta_{i}\right) \cdot \operatorname{Pr}\left(D_{i, \hat{g}, \hat{c}}=1 \mid X_{i}, \theta_{i}\right)
$$

\footnotetext{
${ }^{8}$ At the highest grade, $s$ is excluded from the choice set since continuing schooling is impossible.
} 
where $D_{i, b, s}$ is an indicator that is equal to 1 when an individual $i$, who has already completed grade level $b$, chooses to continue in school (chooses option $s)$.

\section{Unobserved Heterogeneity}

In the spirit of Heckman and Singer (1984), we adopt a discrete distribution for unobserved heterogeneity. Assuming that there are $K$ types in the population, ${ }^{9}$ the probability of belonging to type $k, p_{k}$, is estimated by a logistic distribution function:

$$
p_{k}=\frac{\exp q_{k}}{\sum_{s=1}^{K} \exp q_{s}} \quad k=1, \ldots, K
$$

where $q_{k}$ 's are parameters to be estimated, with the restriction that $q_{K}=0$.

Given we use an individual-grade-outcome-specific intercept term in our model specification, $\gamma_{i, g, c}=\alpha_{g, c} \theta_{i}$, the $K$ types distribution induces the estimation of $K$ type-specific intercepts for each outcome equation at each schooling level. Therefore, unobserved heterogeneity in our model has to be interpreted as a vector of schooling and labor market unobserved skills, ability or motivation, whose dimension is $K$ times the number of latent equations modeled. ${ }^{10}$

As a consequence, the mixed likelihood, for an individual $i$, is simply:

$$
L_{i}\left(X_{i}\right)=\sum_{k=1}^{K} p_{k} \cdot L_{i}^{k}\left(X_{i}\right)
$$

where $L_{i}^{k}\left(X_{i}\right)$ is the contribution of the likelihood for an individual of type $k$.

The model is estimated by maximization of the sum of all individual (mixed) log likelihoods.

\footnotetext{
${ }^{9}$ In what follows, we estimate the model with different values of $K$, and determine the optimal number of types using a Bayesian Information Criterion.

10 "School continuation" is the outcome of reference at the end of each grade level. Therefore, there are 3 latent utility equations modeled at the end of each of the 7 grade levels, corresponding to the 3 employment outcomes.
} 


\section{Estimation}

Two versions of the model are estimated. In the first one, the contractual outcomes correspond to the contract types at the beginning of the first job after schooling, up to 1 year. As a consequence, the outcome "out of the labor force" concerns individuals who have no job during the year that follows their exit from schooling. In the second version, the outcomes are the employment status exactly two years after the exit from schooling.

For each version of employment outcomes, the model is estimated separately for French and African-natives. Therefore, each groups has its own unobserved heterogeneity distribution and parameters. A relatively small number of individuals choose to stop schooling at the end of the fist education level (no qualification) in the two sub-samples. Thus, we do not model employment contract outcomes at this level. As a consequence, the choice set at the end of the first education level is either continuing or stopping schooling.

The estimation output of one set of employment outcomes for one subsample consists of a huge set of estimated parameters. A 2 types unobserved heterogeneity distribution requires the estimation of 271 parameters (290 for a 3 types distribution and 309 for a 4 types distribution). The calculation of the effects of interest, such as the impact of attaining a schooling level on the probability of a particular employment outcome, is not summarized by a single parameter. Instead, it involves the combination of parameters associated to unobserved heterogeneity and parameters measuring the effect of observable characteristics.

\section{$5 \quad$ Results}

In this section, we present the results of the different estimations. We first show results about unobserved heterogeneity and the goodness of fit. Secondly, we study the determinants of schooling choices and explain the differences in schooling attainments between the two sub-samples. Finally, we show results on employment outcomes. In particular, we look at the roles of schooling and origin in explaining both first employment outcomes within the first year, and employment outcomes at two years. 


\subsection{Unobserved Heterogeneity and the Goodness of Fit}

\subsubsection{Unobserved Heterogeneity}

In order to determine the optimal number of types for the unobserved heterogeneity distribution, we compare the estimations of the model with 2,3 and 4 types for each origin group and each set of employment outcomes (first outcomes within the first year and outcomes at two years). ${ }^{11}$ The comparison of Bayesian Information Criterion values for the different specifications, shown in Table 1 makes us choosing a 2 types distribution for unobserved heterogeneity.

\section{[TABLE 1 HERE]}

\subsubsection{Goodness of Fit}

From parameter estimates, we compute the simulated schooling grade attainments and employment outcomes for each individual of each sub-sample. According to the estimated unobserved heterogeneity distribution, a random type is assigned to each individual. Then, for each sub-sample, we build the simulated distributions of schooling attainments and employment outcomes, that we compare with the actual distributions. Tables 2 and 3 show the simulated and actual distributions of schooling attainments for French and African-natives respectively, as well as the average grade levels. Tables 4 and 5 show the employment outcomes distributions. All those tables contain the type-specific distributions and average grade as well as the average across types in each sub-sample.

For both groups, the actual and average simulated distributions are very close to each other. Indeed, our model is capable of explaining both schooling attainments and employment outcomes almost perfectly. ${ }^{12}$

Tables 2 and 3 show that African-natives are much less educated than French-natives: more than one grade of difference on average. More precisely, $28 \%$ of French-natives have at most a vocational high school degree (grades

\footnotetext{
${ }^{11}$ Since we want to take into account educational selectivity (Cameron and Heckman, 1998), we disregard a model specification without unobserved heterogeneity.

${ }^{12}$ The evident capacity of the model to fit the data is most likely a by-product of its flexibility.
} 
1 and 2) and $46 \%$ get a college diploma (grades 5 to 7 ), whereas, for Africannatives, those proportions are respectively $54 \%$ and $19 \%$. As seen in Tables 4 and 5, French-natives are also more often employed in Permanent Contracts (PC) (24\% for the first contract vs. $15 \%$ for African-natives, and $43 \%$ vs. $26 \%$ for the contract at two years) and less often unemployed (15\% and $16 \%$ vs. $23 \%$ and $26 \%$ ).

The type-specific patterns in each sub-sample are also very different, which confirms the importance of controlling for unobserved heterogeneity. For French-natives, type 2 individuals tend to reach higher schooling attainments: their average grade is around 5, whereas it is only 3.6 for type 1's, and their distribution is more oriented towards high education levels. Thus, one could interpret unobserved heterogeneity as unobserved academic skills, where type 2 individuals would correspond to high-skilled individuals. Type 2 individuals are also less often employed in Fixed-Term Contracts (53\% vs. $65 \%$ for the first contract, and 30\% vs. $48 \%$ for the contract at 2 years).

For African-natives, the correlation between unobserved heterogeneity and schooling is less clear: the difference between type 1 and 2 average grades is only 0.3. Concerning the grade distribution, even if the proportion of unqualified is three times as high for type 2 as it is for type 1 (30\% vs. $10 \%$ ), there are also more type 2 college graduates (5\% vs. $0 \%$ ). The majority of type 1 individuals are vocational high school graduates $(51 \%, 15 \%$ for type 2 ), and the proportion of general high school graduates is also higher among type 1 individuals ( $13 \%$ vs. $6 \%$ ).

Concerning the employment outcomes, it turns out that type 2 individuals are much less often firstly employed in PC (8\% vs. $22 \%$ ), and more often unemployed ( $35 \%$ vs. $14 \%$ ), whereas at 2 years, they are more concerned by permanent employment (35\% vs. $18 \%)$.

[TABLE 2 HERE]
[TABLE 3 HERE]
[TABLE 4 HERE]
[TABLE 5 HERE]

\subsection{Schooling Choices}

In this sub-section, we first study the impact of the covariates on schooling attainments. Then, we decompose the gaps in the schooling attainments between French and African-natives into two sources: the first one due to 
behaviors (parameter difference) and the second one due to endowments (covariate difference).

\subsubsection{Determinants}

At each grade level, the decision of continuing schooling to the next grade is explained by observable covariates (parents' occupation, location, gender and "late at school") as well as unobserved heterogeneity. In order to assess the relative impact of those different factors, we perform a variance decomposition on the attainment of three grade levels: high school completion and above (which corresponds to reaching level 3 or more), higher education diploma and above (level 5 or more) and college graduation (level 7).

We group the dummies for parents' occupation, living in an urban area and gender in a "parents' background" category. ${ }^{13}$

For each schooling attainment, we regress the simulated grade attainment dummies on each group of explanatory factors separately. Then, we compute the relative share of each group in explaining the grade attainment as the ratio of the corresponding $R^{2}$ over the sum of $R^{2}$ 's of each regression.

Table 6 contains the results of this variance decomposition for French and African-natives separately. The results confirm the importance of unobserved heterogeneity in explaining the schooling attainments for Frenchnatives, where its relative share ranges from 24 to $34 \%$. This share is lower for African-natives (8 to 25\%).

Parents' background is a key determinant of the schooling attainments, especially at high grades: it explains 59 and $58 \%$ of the variance of reaching college graduation for French and African-natives respectively, whereas it accounts for less than one third of the variance of reaching high school completion (29 and 26\%). This pattern may reflect a certain degree of intergenerational immobility: children born from richer and more qualified parents are more likely to obtain a higher education diploma. As a consequence, family background plays a minor role in obtaining low grades, and its importance increases with the grade level.

Early cognitive skills are also a huge determinant of schooling attainments (17 to $37 \%$ for French-natives, 17 to $64 \%$ for African-natives). Interestingly, the pattern across grades is the opposite of parents' background: the importance of "late at school" is higher at low grades. One possible explanation

\footnotetext{
${ }^{13}$ Removing the gender dummy from this category has a very limited impact on the results.
} 
is that among the set of individuals late at school, are those who are very weak academically, but there may be also a set of individuals who were late for exogenous reasons (some bad luck), and were therefore capable of recuperating. Thus, among the late at school individuals, it is likely to find a higher proportion of weak academic individuals at low grades, and a higher proportion of individuals delayed for exogenous reasons at high grades.

\section{[TABLE 6 HERE]}

Then, we merge the simulated samples of French and African-natives and perform a variance decomposition on this full sample. We introduce origin as an explanatory factor, which captures differences in parameters as well as differences in unobserved heterogeneity. Consequently, the relative share of the variance assigned to the "origin" factor is the variance due to the parameters and unobserved heterogeneity together.

The results of the variance decomposition for the full sample are shown in Table 7. The relative shares of parents' background and late at school, and their evolution across the grade levels, are close to the ones we saw in the separate-sample decompositions. The results indicate that, relative to other factors, the impact of ethnic origin is very small: it explains 3 to $5 \%$ of the schooling attainments variances. This result suggests that the difference in schooling attainments between French and African-natives is mainly explained by observable characteristics. Our results are consistent with the huge impact of long run factors in explaining schooling attainments, as documented by Cameron and Heckman (1998) and Eckstein and Wolpin (1999).

\section{[TABLE 7 HERE]}

\subsubsection{Decomposition of Schooling Gaps Between Origin Groups}

In this part, we study schooling attainment gaps between French and Africannatives. We perform a decomposition of the difference in the predicted probabilities of reaching grades 3,5 and 7 . For those three grade levels, we compute the predicted gap, i.e. the gap in the predicted probabilities between the two groups. ${ }^{14}$ This gap is decomposed into two parts: the part due to behaviors (parameters), and the part due to endowments (covariates). ${ }^{15}$

\footnotetext{
${ }^{14}$ The predicted gaps are very close to the gaps actually observed in the population.

${ }^{15}$ The terminology "behaviors" vs. "endowments" is used here to be consistent with the distinction made in empirical work. Technically speaking, this terminology may be
} 
Let $\widehat{\beta}_{A}$ be the estimated parameter vector of individuals with two African parents and $\widehat{\beta}_{F}$, the estimated vector for French-natives. Let $X_{A}$ and $X_{F}$ denote their respective covariate distributions and $\operatorname{Pr}($.$) be the probability$ of interest. The difference in the predicted graduation probabilities can be decomposed into the two following ways:

$$
\begin{array}{cc}
E_{X_{F}}\left[\operatorname{Pr}\left(X_{F}^{\prime} \widehat{\beta}_{F}\right)\right]-E_{X_{A}}\left[\operatorname{Pr}\left(X_{A}^{\prime} \widehat{\beta}_{A}\right)\right] \\
=\quad \text { gap due to behaviors }+ \text { gap due to endowments } \\
=E_{X_{F}}\left[\operatorname{Pr}\left(X_{F}^{\prime} \widehat{\beta}_{F}\right)-\operatorname{Pr}\left(X_{F}^{\prime} \widehat{\beta}_{A}\right)\right]+\left[E_{X_{F}}\left[\operatorname{Pr}\left(X_{F}^{\prime} \widehat{\beta}_{A}\right)\right]-E_{X_{A}}\left[\operatorname{Pr}\left(X_{A}^{\prime} \widehat{\beta}_{A}\right)\right]\right] \\
=E_{X_{A}}\left[\operatorname{Pr}\left(X_{A}^{\prime} \widehat{\beta}_{F}\right)-\operatorname{Pr}\left(X_{A}^{\prime} \widehat{\beta}_{A}\right)\right]+\left[E_{X_{F}}\left[\operatorname{Pr}\left(X_{F}^{\prime} \widehat{\beta}_{F}\right)\right]-E_{X_{A}}\left[\operatorname{Pr}\left(X_{A}^{\prime} \widehat{\beta}_{F}\right)\right]\right]
\end{array}
$$

In equation (5) (resp. (6)), the behavior gap is the gap due to parameters when the distribution of African-natives' (resp. French-natives') covariates is set to the distribution of French-natives (resp. African-natives). ${ }^{16}$

Table 8 reports the sample analogues of the predicted gaps, and the gaps due to behaviors, computed from both equations (5) and (6). ${ }^{17}$ A positive gap corresponds to a lower probability for African-natives.

For the three schooling grades considered, we can see that African-natives have significant lower probabilities of grade attainment: 26 percentage points for high school completion and more, 28 for obtaining a university diploma, and 9 for college graduation. For the gap in the attainment of high school and more, the difference due to parameters is not significant, which means that the whole gap is explained by differences in the observable characteristics between French and African-natives. Concerning the probability of obtaining a higher education diploma, the difference due to parameters ranges from 10 to 21 percentage points, which corresponds to 36 to $76 \%$ of the predicted gap. Finally, 32 to $49 \%$ of the college graduation gap, is explained by the parameters.

Those results suggest that, at low schooling levels, only endowments matter for deciding to continue schooling investment, whereas behaviors turn to be important for the continuation decision at higher grades. Moreover, we can

seen as abusive. Indeed, unobserved heterogeneity, which is evaluated in our analysis, is considered here as "behaviors", whereas it could also be considered as "endowments".

${ }^{16}$ The vectors of parameters, $\widehat{\beta}_{F}$ and $\widehat{\beta}_{A}$, contain the parameters of the unobserved heterogeneity distributions. As a consequence, "gap due to behaviors" corresponds to the difference in probabilities due to behavioral parameters and unobserved heterogeneity.

${ }^{17}$ The gap due to endowments is not reported in the table since it equals the difference between the predicted and behavior gaps. 
remark that the gap due to parameters is much higher when it is computed with French-natives covariates (5), rather than African-natives's (6). Since French-natives covariates distribution corresponds to a higher socioeconomic background, this result suggests that differences in behaviors between French and African natives play a higher role in the upper scale of the socioeconomic scale.

\section{[TABLE 8 HERE]}

\section{Employment Outcomes}

In this section, we examine the determinants of the employment outcomes for both origin groups, as well as the differences across groups. In particular, we study the impact of schooling, which is treated as endogenous in our model. We show the results that concern both the employment outcomes during the first year after school completion, as well as the employment outcomes two years after.

\subsection{Impact of Schooling}

We compute the type-specific predicted probabilities of being employed in a Permanent Contract, employed in a Fixed Term Contract, and being unemployed. Those probabilities are computed at the sample modes, for the following grade levels: vocational and general high school (grades 2 and 3), low college (dropouts and 2 years graduates - grades 4 and 5), high college (3 years and more - grades 6 and 7 ). Then, we compute the differences in the contractual outcome probabilities between the grade levels and their standard errors. The differences measure the impact of attaining the next grade level on the probabilities to be employed in a PC, FTC or being unemployed, other factors remaining fixed. The impacts on the probability of being employed in a PC can be interpreted as "returns to schooling" on permanent employment incidence. This term is used about returns of investment in education on earnings. As an illustration, estimation results of Aeberhardt et al. (2007) show positive marginal returns to schooling on wages of both French-natives and second generation immigrants from Africa. Here, however, we do not focus on wages, but we study whether or not investing in education increases the likelihood of being employed in a PC. This issue is of 
particular interest if workers on the labor market attach more value to jobs offering a stable employment situation.

Table 9 contains results for French-natives and Table 10 results for Africannatives. The next subsection discusses the impact of schooling on employment in a PC and unemployment.

\section{[TABLE 9 HERE]}

[TABLE 10 HERE]

\subsubsection{Permanent Contracts}

For French-natives of type 2, low college attainment has a negative impact on the PC employment probability (38 percentage points for the 1st contract, 33 for the contract at 2 years), compared to high school completion. However, continuing from low to high college has a positive impact (40 and 34 percentage points). Those numerical effects have to be interpreted as upper bounds for the whole French-natives sample, since the differences for type 1 have most of the time a reverse sign with a much lower magnitude, which makes them sometimes insignificant.

Concerning African-natives, the high values of the standard errors make the estimates poorly precise. Only the difference in the likelihood of obtaining a PC during the first year after schooling between low and high college for type 2 is significant and high ( 85 percentage points).

\subsubsection{Unemployment/Out of the Labor Force}

Increasing the education level has a positive impact on the French-natives probability of being unemployed during the first year after schooling. Indeed, attaining low college increases the probability by 3 percentage points for type 1 and 12 percentage points for type 2, whereas the impact of high college is small (non significant for type 1, 3 percentage points for type 2). Concerning unemployment 2 years after schooling, the impact of low college is negative for type 1 and positive for type 2 (10 percentage points in both cases). The impact of high college has the opposite sign for both types (increase of 10 percentage points for type 1 and decrease of 14 percentage points for type 2).

Again, for African-natives, results are barely significant. We can only note that there is a huge negative impact of low college on the probability 
of remaining unemployed during the first year after schooling (76 percentage points).

\subsection{Importance of Schooling vs. Permanent Factors}

We now determine the importance of schooling, relative to other factors, in explaining the employment outcomes. We conduct a variance decomposition of the simulated PC outcome. We regress the simulated PC outcome dummy on each group of explanatory factors separately and compute the share of each factor as the ratio between the corresponding $R^{2}$ and the sum of $R^{2}$ 's of each regression. "Simulated schooling" is added as a new group of explanatory factors, on top of the groups already introduced in the variance decomposition of the schooling attainments: parents' background, late at school and unobserved heterogeneity.

Table 11 contains the results of this variance decomposition for French and African-natives separately. Schooling explains a great part compared to other explanatory factors. In particular, its impact is twice as high as the impact of parents' background, except for the 1st contract within the 1st year for African-natives. Delay during primary school has a very small impact on the contractual outcomes ( $6 \%$ and less). This confirms that this variable has to be interpreted mostly as a measure of cognitive skills (as opposed to some sort of labor market skill), since we already noticed in section 5.2.1 that its impact on schooling attainments was as important as parents' background. Unobserved heterogeneity is a huge determinant: it explains 17 to $20 \%$ of the permanent employment probability variance for French-natives (as high as Parents' background) and 30 to $40 \%$ for African-natives (as high as schooling).

\section{[TABLE 11 HERE]}

Then, we do the same decomposition on the full sample, which contains the simulated outcomes of French and African-natives together. Parents' origin is introduced as a new explanatory factor, whereas unobserved heterogeneity is removed, since its distribution is origin specific.

Table 12 contains the results of this variance decomposition. It shows that schooling attainments explain $68 \%$ of the cross-sectional variance in employment under a Permanent Contract for the first job after schooling. Thus, $32 \%$ of the variance are not explained by observed investment in human capital. Differences in observable characteristics or behaviors and discrimination 
may be possible explanations of the gap in permanent employment between French and African-natives. Moreover, two years after the exit from school, the schooling impact decreases to $62 \%$. There may be other observable human capital factors, such as experience, that may have a return on the access to permanent employment at that time.

\section{[TABLE 12 HERE]}

\section{Conclusion}

In this paper, we estimated a flexible dynamic model of education choices and early employment contract outcomes. The model was estimated separately for Second-Generation Immigrants born of African parents, and the equivalent sub-population of French-natives.

We found that parental background is the main determinant of schooling attainments at high grade levels for French and African-natives. Compared to other factors, it explains about $60 \%$ of the variance of completing five years of college for both French and African-natives. Concerning the attainment of lower grade levels, however, the impact of parental background is much lower (around 30\% for the probability of attaining at least secondary education completion) but still the same for both origin groups. At that grade level, the two sub-samples differ according to the size of the relative impact of "delay during primary school" (59\% for African-natives, 37\% for French-natives) and unobserved heterogeneity (15 and $34 \%$ respecively).

Then, we found that origin-specific unobserved heterogeneity and parameters seem to explain a small part of the schooling gap between French and African-natives. Concerning early career employment outcomes, schooling attainments explain $68 \%$ of the employment under a Permanent Contract in the whole sample for the first employment period in the labor market after schooling. This result implies that there are still $32 \%$ that are not explained by observed investment in human capital. Two years after the exit from school, this unexplained part increases to $38 \%$. Thus, unobserved factors, differences in behavior or discrimination may all be viewed as possible reasons explaining a significant gap in access to early career job stability. 


\section{References}

Aeberhardt, R., D. Fougère, J. Pouget, and R. Rathelot. 2007. "Wages and Employment of French Workers with African Origin." IZA Discussion Paper No. 2898, July.

Aeberhardt, R., and J. Pouget. 2007. "National Origin Wage Differentials in France: Evidence from Matched Employer-Employee Data." IZA, Discussion Paper No. 2779, May.

Belzil, C. 2007. "Testing the Specification of the Mincerian Wage Equation." Annals of Economics and Statistics forthcoming.

Belzil, C., and J. Hansen. 2008. "Calibration and IV Estimation of a Wage Outcome Equation in a Dynamic Environment." IZA Discussion Paper No. 3528, June.

Bentolila, S., and G. Bertola. 1990. "Firing Costs and Labour Demand: How Bad is Eurosclerosis?" Review of Economic Studies 57:381-402.

Bertola, G. 1990. "Job Security, Employment and Wages." European Economic Review 34:851-886.

Cameron, S.V., and J.J. Heckman. 2001. "The Dynamics of Educational Attainment for Black, Hispanic, and White Males." Journal of Political Economy 109:455-499.

—. 1998. "Life Cycle Schooling and Dynamic Selection Bias: Models and Evidence for Five Cohorts of American Males." Journal of Political Economy 106:262-233.

Card, D. 2005. "Is the New Immigration Really So Bad?" The Economic Journal 115:F300-F323.

Chiswick, B.R., and N. DebBurman. 2004. "Educational Attainment: Analysis by Immigrant Generation." Economics of Education Review 23:361379 .

Eckstein, Z., and K.I. Wolpin. 1999. "Why Youths Drop out of High School: The Impact of Preferences, Opportunities, and Abilities." Econometrica 67:1295-1339. 
Garibaldi, P. 1998. "Job Flow Dynamics and Firing Restrictions." European Economic Review 42:245-275.

Heckman, J.J., and B. Singer. 1984. "A Method for Minimizing the Impact of Distributional Assumptions in Econometric Models for Duration Data." Econometrica 52:271-320.

Keane, M.P. 2006. "Structural vs. Atheoretic Approaches to Econometrics." Journal of Econometrics, pp. .

McFadden, D.L. 1974. Frontiers in Econometrics, New York Academic Press, chap. Conditional Logit Analysis of Qualitative Choice Behavior.

Mortensen, D.T., and C.A. Pissarides. 1999. "Unemployment Responses to 'Skill-Biased' Technology Shocks: The Role of Labour Market Policy." The Economic Journal 109:242-265.

Nielsen, H.S., M. Rosholm, N. Smith, and L. Husted. 2003. "The School-toWork Transition of 2nd Generation Immigrants in Denmark." Journal of Population Economics 16:755-786.

OECD. 1999. "Employment Outlook." Report, OECD Paris.

Van Ours, J.C., and J. Veenman. 2003. "The Educational Attainment of Second-Generation Immigrants in The Netherlands." Journal of Population Economics 16:739-753. 
Table 1: Bayesian Information Criterion Values for Model Selection

\begin{tabular}{lcc}
\hline & French-natives & African-natives \\
\hline \multicolumn{3}{l}{ First employment outcome within the first year } \\
\hline 4 types & 206644.29 & 12030.97 \\
3 types & 206528.13 & 11948.08 \\
2 types & 206326.80 & 11798.42 \\
\hline \multicolumn{3}{c}{ Employment outcome at 2 years } \\
\hline 4 types & 214163.45 & 12511.16 \\
3 types & 213983.91 & 12380.89 \\
2 types & 213837.91 & 12281.88 \\
\hline
\end{tabular}

Note: The number of estimated parameters of each specification is 309 for the model with 4 types, 290 for the model with 3 types and 271 for the model with 2 types.

Table 2: Actual and Simulated Grade Distributions: French-Natives

\begin{tabular}{ccccc}
\hline & Actual & \multicolumn{3}{c}{ Simulated Sample } \\
\cline { 3 - 5 } Grade & Sample & Average & Type 1 & Type 2 \\
\hline 1 & 0.060 & 0.059 & 0.088 & 0.000 \\
2 & 0.225 & 0.227 & 0.315 & 0.051 \\
3 & 0.147 & 0.147 & 0.142 & 0.157 \\
4 & 0.108 & 0.106 & 0.109 & 0.101 \\
5 & 0.207 & 0.207 & 0.152 & 0.314 \\
6 & 0.136 & 0.137 & 0.122 & 0.169 \\
7 & 0.118 & 0.118 & 0.073 & 0.207 \\
\hline Average & & & & \\
Grade & 4.057 & 4.060 & 3.579 & 5.013 \\
\hline
\end{tabular}


Table 3: Actual and Simulated Grade Distributions: African-Natives

\begin{tabular}{ccccc}
\hline & Actual & \multicolumn{3}{c}{ Simulated Sample } \\
\cline { 3 - 5 } Grade & Sample & Average & Type 1 & Type 2 \\
\hline 1 & 0.210 & 0.203 & 0.104 & 0.304 \\
2 & 0.332 & 0.335 & 0.514 & 0.153 \\
3 & 0.097 & 0.098 & 0.135 & 0.060 \\
4 & 0.174 & 0.185 & 0.104 & 0.267 \\
5 & 0.102 & 0.101 & 0.081 & 0.122 \\
6 & 0.058 & 0.054 & 0.058 & 0.049 \\
7 & 0.026 & 0.025 & 0.004 & 0.046 \\
\hline Average & & & & \\
Grade & 2.903 & 2.906 & 2.735 & 3.079 \\
\hline
\end{tabular}

Table 4: Actual and Simulated Employment Outcome Distributions: FrenchNatives

\begin{tabular}{|c|c|c|c|c|}
\hline \multirow[b]{2}{*}{ Grade } & \multirow{2}{*}{$\begin{array}{l}\text { Actual } \\
\text { Sample }\end{array}$} & \multicolumn{3}{|c|}{ Simulated Sample } \\
\hline & & Average & Type 1 & Type 2 \\
\hline \multicolumn{5}{|c|}{ First employment outcome within the first year } \\
\hline $\mathrm{PC}$ & 0.239 & 0.240 & 0.207 & 0.302 \\
\hline FTC & 0.612 & 0.610 & 0.655 & 0.527 \\
\hline Out & 0.149 & 0.150 & 0.138 & 0.171 \\
\hline \multicolumn{5}{|c|}{ Employment outcome at 2 years } \\
\hline $\mathrm{PC}$ & 0.434 & 0.435 & 0.382 & 0.509 \\
\hline FTC & 0.405 & 0.404 & 0.477 & 0.300 \\
\hline Out & 0.161 & 0.161 & 0.141 & 0.191 \\
\hline
\end{tabular}


Table 5: Actual and Simulated Employment Outcome Distributions: African-Natives

\begin{tabular}{|c|c|c|c|c|}
\hline \multirow[b]{2}{*}{ Grade } & \multirow{2}{*}{$\begin{array}{c}\text { Actual } \\
\text { Sample }\end{array}$} & \multicolumn{3}{|c|}{ Simulated Sample } \\
\hline & & Average & Type 1 & Type 2 \\
\hline \multicolumn{5}{|c|}{ First employment outcome within the first year } \\
\hline $\mathrm{PC}$ & 0.154 & 0.158 & 0.217 & 0.081 \\
\hline FTC & 0.619 & 0.610 & 0.645 & 0.565 \\
\hline Out & 0.227 & 0.232 & 0.138 & 0.354 \\
\hline \multicolumn{5}{|c|}{ Employment outcome at 2 years } \\
\hline $\mathrm{PC}$ & 0.263 & 0.269 & 0.178 & 0.352 \\
\hline FTC & 0.476 & 0.477 & 0.600 & 0.365 \\
\hline Out & 0.261 & 0.254 & 0.222 & 0.283 \\
\hline
\end{tabular}

Table 6: Variance Decomposition of Schooling Attainments by Origin Groups

\begin{tabular}{ccc}
\hline & French-natives & African-natives \\
\hline \multicolumn{2}{c}{ Reaching level 3 or more (high school completion) } \\
\hline Parents' background & $29 \%$ & $26 \%$ \\
Late at school & $37 \%$ & $59 \%$ \\
Unobserved heterogeneity & $34 \%$ & $15 \%$ \\
\hline \multicolumn{2}{c}{ Reaching level 5 or more } & higher education diploma) \\
\hline Parents' background & $40 \%$ & $28 \%$ \\
Late at school & $33 \%$ & $64 \%$ \\
Unobserved heterogeneity & $28 \%$ & $8 \%$ \\
\hline \multicolumn{2}{c}{ Reaching level 7 or more } & $($ college graduate) \\
\hline Parents' background & $59 \%$ & $58 \%$ \\
Late at school & $17 \%$ & $17 \%$ \\
Unobserved heterogeneity & $24 \%$ & $25 \%$
\end{tabular}


Table 7: Variance Decomposition of Schooling Attainments for the Full Sample

\begin{tabular}{cc}
\hline \multicolumn{2}{c}{ Reaching level 3 or more (high school completion) } \\
\hline Origin & $5 \%$ \\
Parents' background & $42 \%$ \\
Late at school & $53 \%$ \\
\hline Reaching level 5 or more (higher education diploma) \\
\hline Origin & $5 \%$ \\
Parents' background & $52 \%$ \\
Late at school & $43 \%$ \\
\hline Reaching level 7 or more (college graduate) \\
\hline Origin & $3 \%$ \\
Parents' background & $75 \%$ \\
Late at school & $22 \%$
\end{tabular}

Table 8: Schooling Gaps Decompositions

\begin{tabular}{lcc}
\hline \multicolumn{4}{c}{$\Delta \operatorname{Pr}(s \geq 3)$ (high school completion) } \\
\hline Predicted gap & 0.261 & $(0.095)$ \\
Gap due to behaviors (5) & 0.164 & $(0.088)$ \\
Gap due to behaviors (6) & 0.083 & $(0.095)$ \\
\hline$\Delta \operatorname{Pr}(s \geq 5)$ (higher education diploma) \\
\hline Predicted gap & 0.277 & $(0.054)$ \\
Gap due to behaviors (5) & 0.211 & $(0.056)$ \\
Gap due to behaviors (6) & 0.100 & $(0.053)$ \\
\hline \multicolumn{4}{c}{$\Delta \operatorname{Pr}(s \geq 7)($ college graduate) } \\
\hline Predicted gap & 0.093 & $(0.014)$ \\
Gap due to behaviors (5) & 0.046 & $(0.021)$ \\
Gap due to behaviors (6) & 0.030 & $(0.014)$ \\
\hline
\end{tabular}

Note: In parenthesis: Standard errors computed using the Cholesky factorization method. 
Table 9: Schooling Returns: French-Natives

\begin{tabular}{|c|c|c|c|c|}
\hline & \multicolumn{2}{|c|}{ Type 1} & \multicolumn{2}{|c|}{ Type 2} \\
\hline \multicolumn{5}{|c|}{ First employment outcome within the first year } \\
\hline $\operatorname{Pr}(\mathrm{PC} \mid s=4,5)-\operatorname{Pr}(\mathrm{PC} \mid s=2,3)$ & 0.050 & $(0.013)$ & -0.376 & $(0.017)$ \\
\hline $\operatorname{Pr}(\mathrm{FTC} \mid s=4,5)-\operatorname{Pr}(\mathrm{FTC} \mid s=2,3)$ & -0.076 & $(0.017)$ & 0.258 & $(0.019)$ \\
\hline $\operatorname{Pr}(\mathrm{OUT} \mid s=4,5)-\operatorname{Pr}(\mathrm{OUT} \mid s=2,3)$ & 0.026 & $(0.011)$ & 0.118 & $(0.014)$ \\
\hline $\operatorname{Pr}(\mathrm{PC} \mid s=6,7)-\operatorname{Pr}(\mathrm{PC} \mid s=4,5)$ & -0.034 & $(0.026)$ & 0.398 & $(0.014)$ \\
\hline $\operatorname{Pr}(\mathrm{FTC} \mid s=6,7)-\operatorname{Pr}(\mathrm{FTC} \mid s=4,5)$ & 0.026 & $(0.021)$ & -0.428 & $(0.016)$ \\
\hline $\operatorname{Pr}(\mathrm{OUT} \mid s=6,7)-\operatorname{Pr}(\mathrm{OUT} \mid s=4,5)$ & 0.008 & $(0.016)$ & 0.030 & $(0.011)$ \\
\hline \multicolumn{5}{|c|}{ Employment outcome at 2 years } \\
\hline $\operatorname{Pr}(\mathrm{PC} \mid s=4,5)-\operatorname{Pr}(\mathrm{PC} \mid s=2,3)$ & 0.166 & $(0.038)$ & -0.330 & $(0.013)$ \\
\hline $\operatorname{Pr}(\mathrm{FTC} \mid s=4,5)-\operatorname{Pr}(\mathrm{FTC} \mid s=2,3)$ & -0.069 & $(0.023)$ & 0.228 & $(0.013)$ \\
\hline $\operatorname{Pr}(\mathrm{OUT} \mid s=4,5)-\operatorname{Pr}(\mathrm{OUT} \mid s=2,3)$ & -0.097 & $(0.018)$ & 0.101 & $(0.009)$ \\
\hline $\operatorname{Pr}(\mathrm{PC} \mid s=6,7)-\operatorname{Pr}(\mathrm{PC} \mid s=4,5)$ & -0.106 & $(0.013)$ & 0.344 & $(0.011)$ \\
\hline $\operatorname{Pr}(\mathrm{FTC} \mid s=6,7)-\operatorname{Pr}(\mathrm{FTC} \mid s=4,5)$ & 0.011 & $(0.012)$ & -0.201 & $(0.010)$ \\
\hline $\operatorname{Pr}(\mathrm{OUT} \mid s=6,7)-\operatorname{Pr}(\mathrm{OUT} \mid s=4,5)$ & 0.095 & $(0.006)$ & -0.143 & $(0.008)$ \\
\hline
\end{tabular}

Note 1: Predicted probabilities are computed for a man having a white collar father, a white collar mother, living in a urban area and not having been delayed at school.

Note 2: In parenthesis: Standard errors computed using the Cholesky factorization method. 
Table 10: Schooling Returns: African-Natives

\begin{tabular}{|c|c|c|c|c|}
\hline & \multicolumn{2}{|c|}{ Type 1} & \multicolumn{2}{|c|}{ Type 2} \\
\hline \multicolumn{5}{|c|}{ First employment outcome within the first year } \\
\hline $\operatorname{Pr}(\mathrm{PC} \mid s=4,5)-\operatorname{Pr}(\mathrm{PC} \mid s=2,3)$ & 0.305 & $(0.358)$ & -0.013 & $(0.035)$ \\
\hline $\operatorname{Pr}(\mathrm{FTC} \mid s=4,5)-\operatorname{Pr}(\mathrm{FTC} \mid s=2,3)$ & -0.643 & $(0.785)$ & 0.771 & $(0.145)$ \\
\hline $\operatorname{Pr}(\mathrm{OUT} \mid s=4,5)-\operatorname{Pr}(\mathrm{OUT} \mid s=2,3)$ & 0.338 & $(0.612)$ & -0.757 & $(0.144)$ \\
\hline $\operatorname{Pr}(\mathrm{PC} \mid s=6,7)-\operatorname{Pr}(\mathrm{PC} \mid s=4,5)$ & -0.471 & $(0.280)$ & 0.851 & $(0.094)$ \\
\hline $\operatorname{Pr}(\mathrm{FTC} \mid s=6,7)-\operatorname{Pr}(\mathrm{FTC} \mid s=4,5)$ & 0.579 & $(0.636)$ & -0.763 & $(0.086)$ \\
\hline $\operatorname{Pr}(\mathrm{OUT} \mid s=6,7)-\operatorname{Pr}(\mathrm{OUT} \mid s=4,5)$ & -0.107 & $(0.523)$ & -0.088 & $(0.087)$ \\
\hline \multicolumn{5}{|c|}{ Employment outcome at 2 years } \\
\hline $\operatorname{Pr}(\mathrm{PC} \mid s=4,5)-\operatorname{Pr}(\mathrm{PC} \mid s=2,3)$ & -0.240 & $(0.649)$ & -0.064 & $(0.317)$ \\
\hline $\operatorname{Pr}(\mathrm{FTC} \mid s=4,5)-\operatorname{Pr}(\mathrm{FTC} \mid s=2,3)$ & 0.336 & $(0.407)$ & 0.106 & $(0.168)$ \\
\hline $\operatorname{Pr}(\mathrm{OUT} \mid s=4,5)-\operatorname{Pr}(\mathrm{OUT} \mid s=2,3)$ & -0.096 & $(0.481)$ & -0.041 & $(0.232)$ \\
\hline $\operatorname{Pr}(\mathrm{PC} \mid s=6,7)-\operatorname{Pr}(\mathrm{PC} \mid s=4,5)$ & 0.399 & $(0.370)$ & 0.133 & $(0.141)$ \\
\hline $\operatorname{Pr}(\mathrm{FTC} \mid s=6,7)-\operatorname{Pr}(\mathrm{FTC} \mid s=4,5)$ & -0.537 & $(0.356)$ & -0.056 & $(0.125)$ \\
\hline $\operatorname{Pr}(\mathrm{OUT} \mid s=6,7)-\operatorname{Pr}(\mathrm{OUT} \mid s=4,5)$ & 0.137 & $(0.194)$ & -0.077 & $(0.101)$ \\
\hline
\end{tabular}

Note 1: Predicted probabilities are computed for a man having a white collar father, an unemployed mother, living in a urban area and not having been delayed at school.

Note 2: In parenthesis: Standard errors computed using the Cholesky factorization method. 
Table 11: Variance Decomposition of Obtaining a Permanent Contract by Origin Groups

\begin{tabular}{ccc}
\hline & French-natives & African-natives \\
\hline \multicolumn{2}{c}{ First employment outcome within the first year } \\
\hline Parents' background & $22 \%$ & $38 \%$ \\
Late at school & $3 \%$ & $1 \%$ \\
Unobserved heterogeneity & $17 \%$ & $30 \%$ \\
Simulated schooling & $59 \%$ & $32 \%$ \\
\hline \multicolumn{2}{c}{ Employment outcome at two years } \\
\hline Parents' background & $19 \%$ & $19 \%$ \\
Late at school & $6 \%$ & $0 \%$ \\
Unobserved heterogeneity & $20 \%$ & $40 \%$ \\
Simulated schooling & $54 \%$ & $41 \%$ \\
\hline
\end{tabular}

Table 12: Variance Decomposition of Obtaining a Permanent Contract for the Full Sample

\begin{tabular}{cc}
\hline \multicolumn{2}{c}{ First employment outcome within the first year } \\
\hline Origin & $3 \%$ \\
Parents' background & $26 \%$ \\
Late at school & $3 \%$ \\
Simulated schooling & $68 \%$ \\
\hline Employment outcome at two years \\
\hline Origin & $6 \%$ \\
Parents' background & $24 \%$ \\
Late at school & $8 \%$ \\
Simulated schooling & $62 \%$ \\
\hline
\end{tabular}

